\title{
Commentary: Midaortic syndrome—What is the skinny?
}

\author{
Demetrios N. Mallios, MD, and S. Ram Kumar, MD, PhD, FACS
}

\footnotetext{
From the Division of Cardiac Surgery, Department of Surgery, Keck School of Medicine of the University of Southern California, Los Angeles, Calif; and Heart Institute, Children's Hospital Los Angeles, Los Angeles, Calif.

Disclosures: Authors have nothing to disclose with regard to commercial support.

This work was supported in part by Grant K08HL121191 of the National Heart, Lung, and Blood Institute to S.R.K. and a Heart and Lung Surgery Foundation grant to D.N.M.

Received for publication Jan 9, 2019; accepted for publication Jan 9, 2019; available ahead of print Feb 13, 2019. Address for reprints: S. Ram Kumar, MD, PhD, FACS, Children's Hospital Los Angeles, 4650 Sunset Blvd, Mailstop 66, Los Angeles, CA 90027 (E-mail: rsubramanyan@chla.usc.edu).

J Thorac Cardiovasc Surg 2019;157:e285-6 $0022-5223 / \$ 36.00$

Copyright (c) 2019 by The American Association for Thoracic Surgery https://doi.org/10.1016/j.jtcvs.2019.01.029
}

Midaortic syndrome (MAS) is characterized by narrowing of the descending aorta between the distal aortic arch and the aortic bifurcation. The narrowing may be focal and discrete, or it may be more diffuse along the course of the descending aorta (Figure 1). Not infrequently, the disease process may also extend into visceral arterial branches, such as the celiac, mesenteric, or renal vessels. Most cases of MAS are idiopathic, and the underlying pathogenesis remains poorly understood. In select instances, a link has been established with such conditions as inflammatory arteritis, mucopolysaccharidosis, fibromuscular dysplasia, and Williams syndrome. ${ }^{1}$ Patients typically present for treatment between the ages of 16 and 25 years, with symptoms ranging from hypertension and abdominal angina to, rarely, cardiac failure. ${ }^{2}$ Initial management is symptomatic, primarily aimed at medical control of hypertension. Refractory symptoms or hypoperfusion-related end-organ damage would necessitate interventional therapy. Surgical strategies are dictated by the anatomic extent of the disease process and can include resection of the narrowed segment, patch arterioplasty, or extra-anatomic bypass. ${ }^{1,3}$ More recently, endovascular balloon and stent angioplasty have been used with some success, especially in cases of focal, short-segment narrowing.

A diagnosis of MAS in early childhood is less common, with presentation in the neonatal period being very rare. Symptoms often mimic those of classic coarctation of the aorta. Surgical management of coarctation of the aorta with proximal extension of the hypoplasia into the arch has been well studied. ${ }^{4,5}$ In contrast, limited data are available on the long-term outcomes of intervention for MAS in neonates and infants. The goals of therapy in these patients are complete relief of the obstruction and long-term freedom from reintervention. Treatment options, however, are limited secondary to size constraints and the need to account for somatic growth. Percutaneous interventions such as balloon angioplasty have been used, but the rate of

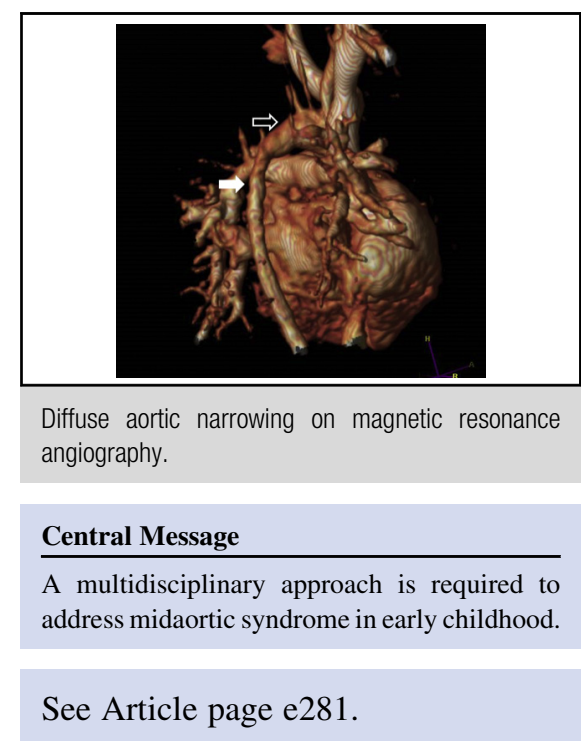

reintervention is high. ${ }^{6}$ The use of stents is plagued by delivery problems, and by the inability of stents in smaller children to dilate to adult vascular diameters. The lack of replacement options limits the applicability of surgical resection of the hypoplastic segment. The relatively low incidence of MAS in infants and neonates makes comparative studies of the various therapeutic interventions challenging.

In this issue of the Journal, Thompson and colleagues ${ }^{7}$ present the interesting case of a 4-month-old infant with MAS who presented in severe heart failure. Because of her small size, she underwent palliation with percutaneous angioplasty and subsequent stenting until she was a candidate for surgical intervention. She then underwent extraanatomic bypass of the hypoplastic segment, which successfully alleviated her symptoms in the short term. Indeed, Thompson and colleagues ${ }^{7}$ are to be commended for effectively managing this particularly difficult problem. Certainly, alternative approaches may also have been feasible. Could they have persisted with percutaneous approaches for a while longer? Thompson and colleagues ${ }^{7}$ chose to construct the proximal anastomosis to the ascending aorta through a sternotomy and with cardiopulmonary bypass, but could they have anastomosed to the proximal descending aorta through a left thoracotomy without the need for bypass? They left additional length on their conduit to allow for somatic growth, but what is the longevity of an 8-mm diameter graft used to bypass a severely narrowed thoracic aorta? Regardless of these 


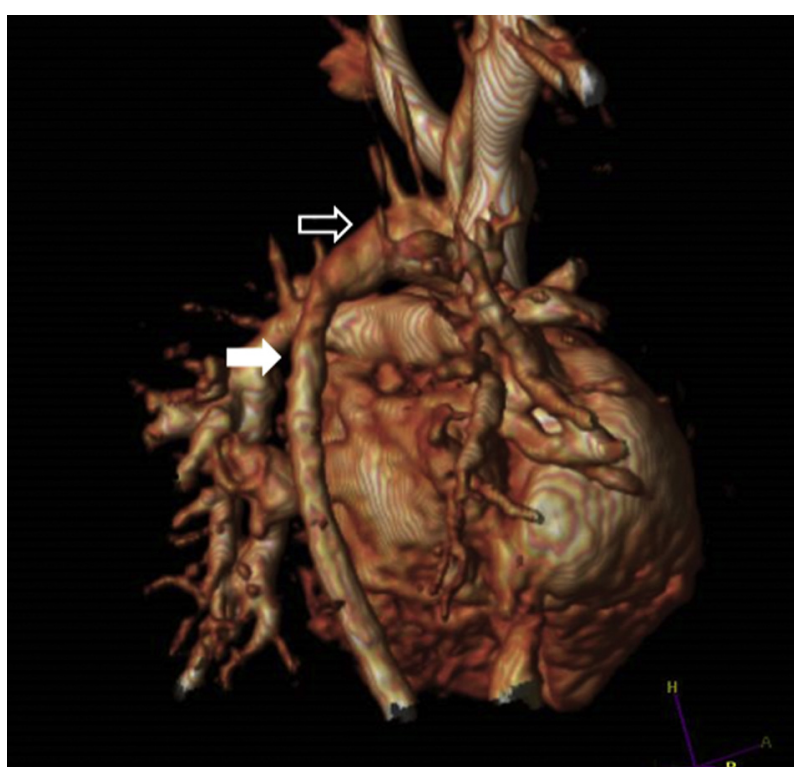

FIGURE 1. Dorsal view of magnetic resonance angiography in a child with diffuse arteriopathy. The distal arch is of normal caliber (open arrow), with moderate diffuse narrowing beginning in the proximal descending thoracic aorta (white arrow) and extending down the entire thoracic aorta.

questions, however, this case elegantly demonstrates that the appropriate management of a young child with MAS requires multidisciplinary collaboration and "out of the box" thinking. The most effective treatment strategy should balance up-front safety and feasibility with longterm freedom from reintervention. Ultimately, technologic advances will pave the way for easily delivered stents that are appropriate for use in a small child and yet have the capability to expand to adult sizes. Similarly, tissueengineered conduits that can keep up with somatic growth would be another welcome solution to tackle such vexing clinical problems.

\section{References}

1. Delis KT, Gloviczki P. Middle aortic syndrome: from presentation to contemporary open surgical and endovascular treatment. Perspect Vasc Surg Endovasc Ther. 2005; 17:187-203.

2. Sen PK, Kinare SG, Engineer SD, Parulkar GB. The middle aortic syndrome. $\mathrm{Br}$ Heart J. 1963;25:610-8.

3. Rumman RK, Nickel C, Matsuda-Abedini M, Lorenzo AJ, Langlois V, Radhakrishnan $\mathrm{S}$, et al. Disease beyond the arch: a systematic review of middle aortic syndrome in childhood. Am J Hypertens. 2015;28: 833-46.

4. Gray WH, Wells WJ, Starnes VA, Kumar SR. Arch augmentation via median sternotomy for coarctation of aorta with proximal arch hypoplasia. Ann Thorac Surg. 2018;106:1214-9.

5. Tulzer A, Mair R, Kreuzer M, Tulzer G. Outcome of aortic arch reconstruction in infants with coarctation: importance of operative approach. J Thorac Cardiovasc Surg. 2016;152:1506-13.e1.

6. Tummolo A, Marks SD, Stadermann M, Roebuck DJ, McLaren CA, Hamilton G, et al. Mid-aortic syndrome: long-term outcome of 36 children. Pediatr Nephrol. 2009;24:2225-32.

7. Thompson JL, Sprouse K, Mir A, Burkhart HM. Successful staged management of neonatal midaortic syndrome. J Thorac Cardiovasc Surg. 2019;157:e281-3. 